Research Article

\title{
Investigation of Bending, Sound Absorption, and Damping Properties of AZ91D-Swivel Plate
}

\author{
Saravanan Annamalai iD, Suresh Periyakgoundar, Kumaravel Paramasivam, \\ and Aravindha Balaji Selvaraj
}

Department of Mechanical Engineering, Sona College of Technology, Salem, 636 005, India

Correspondence should be addressed to Saravanan Annamalai; ansyssaran@gmail.com

Received 9 December 2019; Revised 27 March 2020; Accepted 24 April 2020; Published 22 May 2020

Academic Editor: Stefano Bellucci

Copyright ( $) 2020$ Saravanan Annamalai et al. This is an open access article distributed under the Creative Commons Attribution License, which permits unrestricted use, distribution, and reproduction in any medium, provided the original work is properly cited.

\begin{abstract}
A comparison was made between $\mathrm{Mg}$ alloy and $\mathrm{A} 3$ steel on weight, bending, sound absorption, and vibration conditions. In this study, a swivel plate, which is used in rotating car seats, is to be taken into consideration for finding bending, natural frequency, and frequency under static loading conditions. The swivel plate is generally made up of A3 steel plate; instead, we have replaced that with Mg alloy (AZ91D) plate. Stiffness, flexural strength, natural frequency, frequency under different static loading conditions, and sound absorption capacity were obtained through experimental methods. Finally, it was concluded that the damping capacity of $\mathrm{Mg}$ alloy of swivel plate is higher, has better stiffness, and incurred weight reduction by $26.58 \%$ less than that of the A3 steel. Also, the Mg alloy material exhibits better specific flexural strength, and specific flexural modulus and sound absorption coefficient are $11.76 \%$ and $25 \%$ higher than those of A3 steel at higher frequency level $(2000 \mathrm{~Hz})$ and at lower frequency level $(100 \mathrm{~Hz})$.
\end{abstract}

\section{Introduction}

The excessive noise and vibration on the car seat affect the mental and physical health of driver and passengers. Moreover, they reduce their working performance and efficiency [1]. The vibration and sound absorption characteristics of automobile parts are very important because of passenger comfort and avoiding component failure. Vibrations in different structures occur at different types of frequencies. If a component vibrates at frequencies higher or nearer to the natural frequency of the body, the vibration might be significantly high. Usually car seat models for vibration analysis of the whole body vibration (WBV) have been considered, including vertical, lateral, and longitudinal vibration, as shown in Figure 1. Here we have considered only the revolving part of the rotating car seat, i.e., swivel plate. It is well known that the revolving swivel plate in car seat application is subjected to bending and vibration. Therefore the main objective of this research work is to conduct experimental test for bending, vibration, and sound absorption analysis of swivel plate. Moreover, in the bending, natural frequency and frequency under static loading conditions were obtained using experimental method. The flexural strength and sound absorption capacity of swivel plate were obtained using specimen by experimental method. This analysis considers not only passenger's comfort, regarding the sound absorption and frequency range, but also the load carrying and damping capacity of the swivel plate.

With the development of modern industry and transportation, noise pollution has one of the dangerous environmental problems [2]. In recent days, automobile and aircraft industries are focused on the lightweight and environmental friendly materials with good mechanical properties. Saravanan and Suresh [3] had investigated material replacement for gear and concluded that bronze alloy material is suitable instead of steel, for better strength, load carrying capacity, high velocity, and low-intensity stress level. Prabhakaran et al. [4] had investigated sound and vibration properties of flax fiber-reinforced composites using Data Acquisition system with Lab View software and finally concluded that the sound absorption coefficient of 


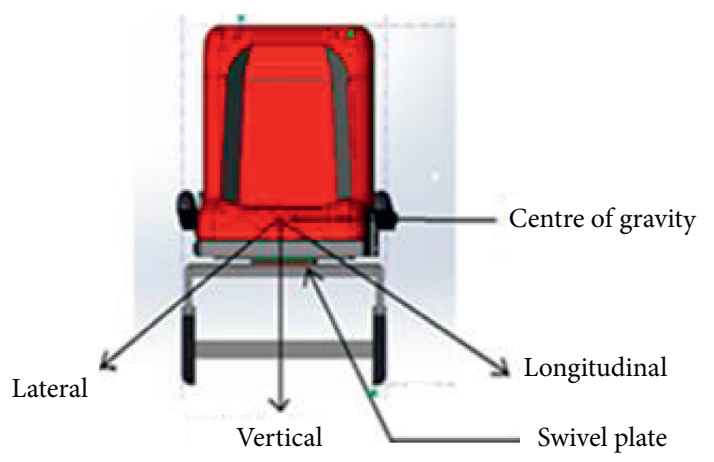

FIgURE 1: Revolving car seat model.

flax fiber-reinforced composites was $21.42 \%$ higher than that of glass fiber-reinforced composites. Also the damping factor was determined by using free vibration method as per the ASTM standard E756. The same experimental setup was utilized in this current sound and vibrational analysis.

Magnesium alloy has drawn a good deal of attention from automotive and aerospace components, due to its low density, high specific strength, and good damping capacity [5]. Also, it has outstanding physical and mechanical properties such as high stiffness/weight ratios, good castability, excellent vibration and shock absorption, and high damping capacity [6]. In automobile industry, the widely used magnesium alloys are $\mathrm{Mg}-\mathrm{Al}-\mathrm{Zn}$ series alloys, which have excellent castability and are of low cost [7-9]. However, the use of $\mathrm{Mg}$ alloys has been limited to a narrow range because of its limited mechanical properties such as low hardness and low tensile strength. Recently, a large number of research studies have focused on improving the mechanical properties of magnesium alloys by alloying $[10,11]$. Moreover the improvement of mechanical properties often results in a decline of damping capacity [12]. For further engineering applications of magnesium, balancing the damping behavior and the mechanical properties has been a critical challenge [13]. Recently, several investigators have reported that the addition of $\mathrm{Ca}, \mathrm{Sr}, \mathrm{Bi}, \mathrm{Sb}$, or rare earth $(\mathrm{RE})$ elements was to effectively improve the mechanical properties for the Mg-Al-Zn series alloys [14, 15]. Wu et al. [16] studied the effect of combined addition of $\mathrm{Ca}$ and $\mathrm{RE}$ elements on the mechanical properties of AZ91D alloy. The result showed that with the combined addition of 1 mass $\%$ of $\mathrm{Ca}$ and $1 \mathrm{mss} \%$ of RE elements to AZ91D alloy, the UTS increased by $15.9 \%$. Chen et al. [17] had investigated the effect of mechanical vibration on microstructure and properties of cast AZ91D-Mg alloy, finally concluding that, with the increase of mechanical amplitude, it can refine the $\beta-\mathrm{Mg}_{17}-\mathrm{Al}_{12}$ phase in AZ91D. Moreover, with the increase of mechanical vibration frequency up to $100 \mathrm{~Hz}$ the tensile strength and yield strength of AZ91D alloy increase gradually, and the tensile strength and yield strength increased by $17.9 \%$ and $10.3 \%$, respectively. The ultimate tensile strength (UTS), yield strength, and elongation of as-cast AZ91D increase with the addition of Y [18]. The results revealed that the mechanical and damping properties of AZ91D could be increased with alloying elements. The chemical composition of AZ91D-Mg alloy is given in Table 1 .

The goal of this study is to explore the load carrying capacity, sound absorbing, and damping properties of $\mathrm{Mg}$ alloy
Table 1: Chemical composition of AZ91D-magnesium Alloy.

\begin{tabular}{lccccccccc}
\hline \multirow{2}{*}{ S. no } & $($ Mass \%) & \multicolumn{1}{c}{ Composition (\%) } \\
& & $\mathrm{Al}$ & $\mathrm{Mn}$ & $\mathrm{Zn}$ & $\mathrm{Si}$ & $\mathrm{Cu}$ & $\mathrm{Ni}$ & $\mathrm{Fe}$ & Other \\
\hline 1 & AZ91D & 8.5 & 0.20 & 0.55 & 0.10 & 0.03 & 0.022 & 0.055 & 0.02 \\
\hline
\end{tabular}

swivel plate compared with A3 steel swivel plate, which is used in the revolving car seat. The revolving seat, which is used in the car, is specially made for physically challenged/ill persons, so damping property plays major role in this type of applications. By utilizing $\mathrm{Mg}$ alloy materials in the fabrication of structures, significant reductions in weight and emissions could be achieved, along with the ability to have materials that are renewable, recyclable, and biodegradable. Moreover, those materials with improved acoustic performance and damping properties will be an environmental friendly solution to the structure-noise challenge, besides several numbers of bending and vibration analyses of $\mathrm{Mg}$ alloy (e.g., $[19,20])$ but only a limited number of studies regarding the combination of bending, vibration, and sound absorption analysis of automobile component especially in car seat parts [21, 22]. To solely investigate the bending, damping and sound absorbing capacity of swivel plate are proposed in to this work. Normally swivel plate is made up of A3 steel plate which we replaced with magnesium (AZ91D) alloy for that application, because the AZ91D alloy has great potential for the applications in suppressing the mechanical vibration and attenuating wave propagation for the control of noise and stabilization of structure components because of their low density and damping capacity. Weijiu Huang et al. [23] investigated about the fretting wear behavior of AZ91D alloy with different numbers of cycle and loading condition compared with AM60B alloy, because they have excellent castability and good mechanical properties with low cost; moreover they have been mainly used to produce the engineering parts such as engine crank case, accelerator brake pedal bracket, instrument board of the cars, and steering wheels and seat [24]. The results showed that AZ91D alloy revealed a higher capability in crack nucleation and propagation and is also a less friction coefficient and is of lower wear quantity than that of AM60B alloy. As is known, the accessories in automobile especially car seat are always subjected to the vibration environment. The fretting damage of car seat parts is unavoidable. For a better life-time swivel plate, the AZ91D material was chosen. However, this paper focused on a methodology that may be used to model a swivel plate that is used for revolving car seat undergoing base vibration.

\section{Materials and Methods}

The material properties of A3 steel and magnesium alloy are tabulated in Table 2 for analyzing purpose.

(i) A3 Tool Steel (UNS 30103)

(ii) Magnesium alloy (AZ91D)

A3 steel swivel plate was purchased from Bherwa Metals Pvt. Ltd. Bangalore, India, which is suitable for revolving seat with standard dimension as given in Table 3. The AZ91D 
TAble 2: Properties of A3 steel and magnesium alloy.

\begin{tabular}{lcccc}
\hline S. no & Properties & Unit & A3 tool steel & Magnesium alloy \\
\hline 1 & Density & $\mathrm{kg} / \mathrm{m}^{3}$ & 7860 & 1810 \\
2 & Modulus of elasticity & $\mathrm{GPa}$ & 205 & 45 \\
3 & Poisson's ratio & - & 0.29 & 0.35 \\
4 & Tensile yield strength & $\mathrm{MPa}$ & 350 & 160 \\
5 & Tensile ultimate strength & $\mathrm{MPa}$ & 420 & 250 \\
\hline
\end{tabular}

TABle 3: Dimensions and weight of Swivel plate.

\begin{tabular}{lccccc}
\hline S. no & Material & Thickness of single plat $(\mathrm{mm})$ & Length $(\mathrm{mm})$ & Width $(\mathrm{mm})$ & Weight $($ grams $)$ \\
\hline 1 & A3 steel & 1.5 & 104 & 104 & 632 \\
2 & Mg alloy & 5 & 104 & 104 & 464 \\
\hline
\end{tabular}

plate was purchased from NUFIT PIPING SOLUTIONS, Mumbai, India. The length and width of the $\mathrm{Mg}$ alloy plate are the same as in the A3 steel plate. The thickness of $\mathrm{Mg}$ alloy plate is increased when compared to A3 steel plate based on human body and car seat weight. The AZ91D plate is mechanically ground, polished by using surface polishing machine, and drilled with vertical drilling machine. In order to achieve revolving feature for $\mathrm{Mg}$ alloy plate, the steel ball bearings with riveted joint were used; finally AZ91D swivel plate was fabricated as shown in Figure 2.

2.1. Design Specification. Figure 2(a) shows A3 steel swivel plate and Figure 2(b) shows Mg alloy swivel plate. The dimensions and weight of the swivel plate for both materials are given in Table 3 .

\section{Bending Analysis}

In this research, bending analysis was carried out to evaluate the deformation behavior of AZ91D material. In order to find out the strength for load carrying capacity of the swivel plate, the bending analysis is a vital one. Moreover, two types of bending analysis were carried out.

(a) Flexural strength measurement analysis

(b) Stiffness measurement analysis

3.1. Flexural Strength Measurement Analysis. The flexural strength measurement was carried out as per the ASTM standard D 790 [25]. This analysis was used to determine the flexural strength and modulus of flexure of both the materials. The AZ91D and A3 steel specimen were tested in 3point bending apparatus with a span to thickness ratio of 8 . In order to achieve better results for both materials, the specimen was prepared with the same thickness as in the corresponding swivel plate for bending analysis. The dimensions of both materials are presented in Table 4 . The specimens were tested using Zwick/Roell Z005 universal testing machine at a crosshead speed of $1.2 \mathrm{~mm} / \mathrm{min}$. The Zwick/Roell universal test machine has a maximum test load of $5 \mathrm{kN}$ and maximum cross-head speed of $3000 \mathrm{~mm} / \mathrm{min}$.
3.2. Stiffness Measurement Analysis. The compression testing was chosen for stiffness measurement with a large range (up to $5 \mathrm{kN}$ ). The A3 steel and Mg alloy (AZ91D) material swivel plates were taken to carry out bending test of various compression loads. The compression test was performed by using a universal testing machine (UTM). Moreover, the compression test was performed by applying compression load on a swivel plate between two platforms of UTM. The load was applied on top surface of the swivel plate with a range from $1 \mathrm{kN}$ to $5 \mathrm{kN}$. The deflection values were taken from dial gauge and load vs deflection values were plotted on the curve as shown in Figure 3.

Let us assume that the maximum load applied to the swivel plate is $300 \mathrm{~kg}$. In order to find out the stiffness for both materials, the swivel plate and the following method were used, where load $=3 * 10^{3} \mathrm{~N}$, because the swivel plate is designed for this load value. In order to obtain an accurate result, it is taken as s maximum load. Now, stiffness for swivel plate $(K)$ for Steel

$$
\begin{aligned}
K_{\text {Steel }} & =\frac{\text { Load }}{\text { Deflection }} \mathrm{N} / \mathrm{m}, \\
K & =\frac{3 * 10^{3}}{7.5 * 10^{-3}}, \\
K_{\text {Steel }} & =4 * 10^{5} \mathrm{~N} / \mathrm{m} .
\end{aligned}
$$

Stiffness for swivel plate $(K)$ for $\mathrm{Mg}$ alloy

$$
\begin{aligned}
K_{\mathrm{Mg}} & =\frac{\text { Load }}{\text { Deflection }} \mathrm{N} / \mathrm{m}, \\
K & =\frac{3 * 10^{3}}{2.3 * 10^{-3}} \\
K_{\mathrm{Mg}} & =13 * 10^{5} \mathrm{~N} / \mathrm{m} .
\end{aligned}
$$

From this numerical analysis, it could be seen that the stiffness value of $\mathrm{Mg}$ alloy swivel plate is significantly higher than that of A3 steel plate. However, the $\mathrm{Mg}$ alloy plate carried significantly more load than the A3 steel plate in the same weight ratio.

\section{Vibration Analysis of Swivel Plate}

Noise, vibration and harshness (NVH) analysis helps improves the vibration attributes of car seat. To study the 


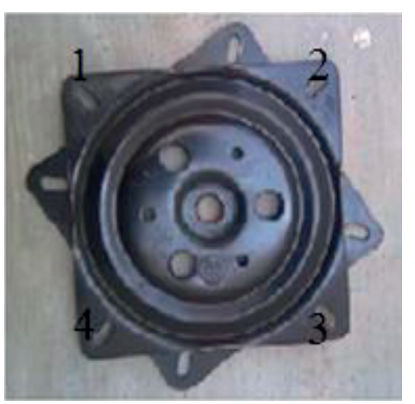

(a)

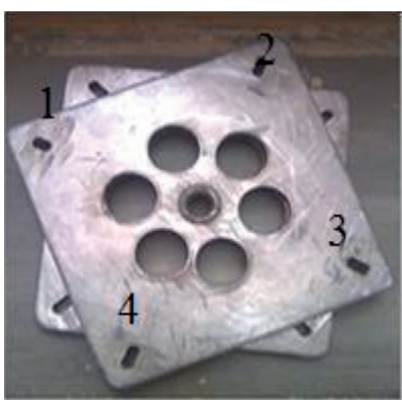

(b)

FIGURE 2: Swivel plate with four location points: (a) A3 steel and (b) Mg alloy.

TABle 4: Dimensions and Weight of Specimen for flexural strength analysis.

\begin{tabular}{lccccc}
\hline S. no & Material & Thickness of single plate $(\mathrm{mm})$ & Length $(\mathrm{mm})$ & Width $(\mathrm{mm})$ & Weight $($ grams $)$ \\
\hline 1. & A3 steel & 1.5 & 125 & 25 & 55 \\
2. & Mg alloy & 5 & 125 & 25 & 41 \\
\hline
\end{tabular}

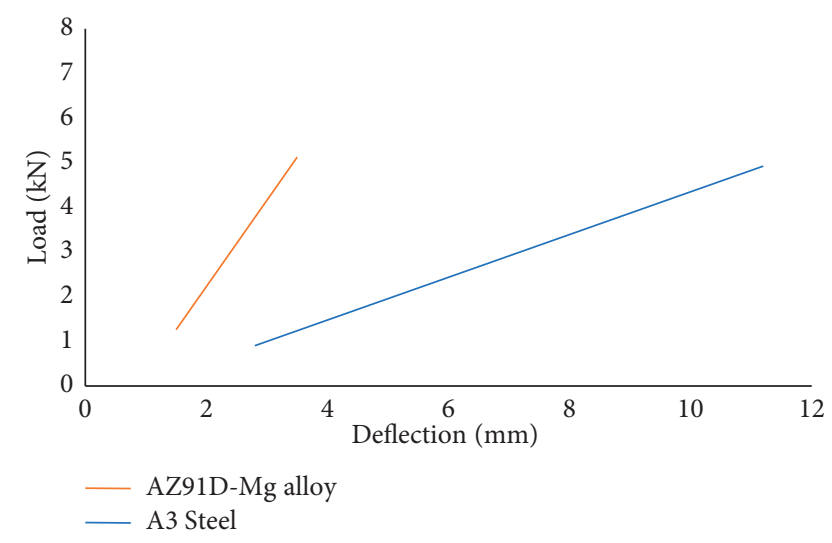

FIGURE 3: Load vs. deflection curve for both materials of swivel plate.

vibration behavior of the system or component a reliable experimental validation is required. Moreover, the experimental analysis is a very important one to investigate the frequency under no loading and loading conditions and also damping absorption capacity of the component. To analyze the swivel plate it is necessary to describe the dimension and geometrical shape. Table 2 shows the dimension and weight of the swivel plates for both materials; also Figure 1 shows the geometrical shape of the swivel plate for both materials. The chemical composition AZ91D material is given in Table 1 and the mechanical properties of both materials are given in Table 2; based on these values the experimental work has been conducted.

4.1. Experimental Analysis of Swivel Plate. The natural frequency and frequency under different loading conditions were obtained using the vibration test setup. The swivel plate is placed on the table and the base four corners touch the ground and the top of the plate is not touched by anyone. An accelerometer sensor supplied by Dytran whose sensitivity is
$10.47 \mathrm{mV} / \mathrm{g}$ was placed at the top of the swivel plate at location points. The location points $1,2,3$, and 4 are shown in Figure 2. The output signals are received by means of connecting the accelerometer sensor with a Data Acquisition (DAQ) card 9234, which is connected to the PC and interfaced with Laboratory Virtual Instrumentation Workshop (Lab VIEW) software supplied by the National Instruments.

Figures 4 and 5 show the time of response for free vibration of A3 steel and Mg alloy swivel plates were obtained from the LABVIEW software. In this experimental method time (sec) of response and frequency response for both materials for no loading and loading conditions were obtained. Time of response and frequency response curves were obtained from LABVIEW for investigating the damping capacity for both materials.

In Figures 4 and 5, it could be seen that the time domain excitation response for $\mathrm{Mg}$ alloy was significantly higher when compared to A3 steel swivel plate under the same excitation force. Because of its less stiffness under no loading condition the $\mathrm{Mg}$ alloy swivel plate exhibits high time domain response amplitude. It is observed that under the no loading condition the time domain response result of the $\mathrm{Mg}$ alloy exhibits low stiffness and vibration absorbing capacity than that of A3 steel.

In Figures 6 and 7, it could be seen that the time domain attenuation response excitation for $\mathrm{Mg}$ alloy was very good when compared to steel swivel plate. Because of its high damping capacity under loading condition the $\mathrm{Mg}$ alloy swivel plate exhibits better vibration amplitude attention response excitation than that of A3 steel. It is observed that under the loading condition the time domain response results of the $\mathrm{Mg}$ alloy swivel plate exhibit better stiffness and vibration absorbing capacity than those of A3 steel swivel plate. Moreover, when there is increasing in load, the time domain excitation of response for $\mathrm{Mg}$ alloy gave better results than that of steel. This is due to its material property and composition of alloying elements. 


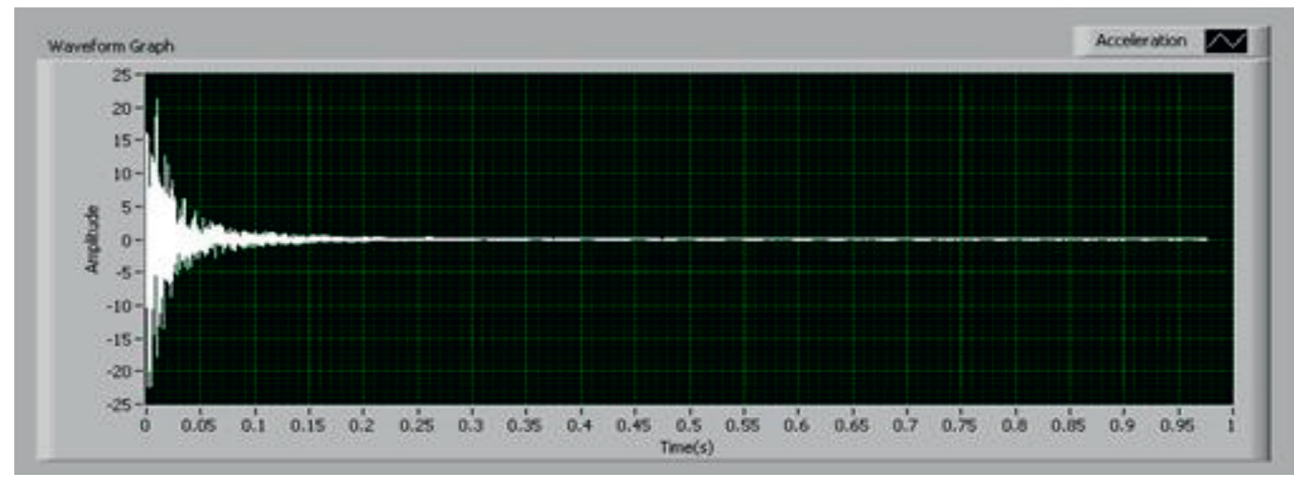

FIgURE 4: Time (sec) domain excitation response of A3 steel under natural frequency.

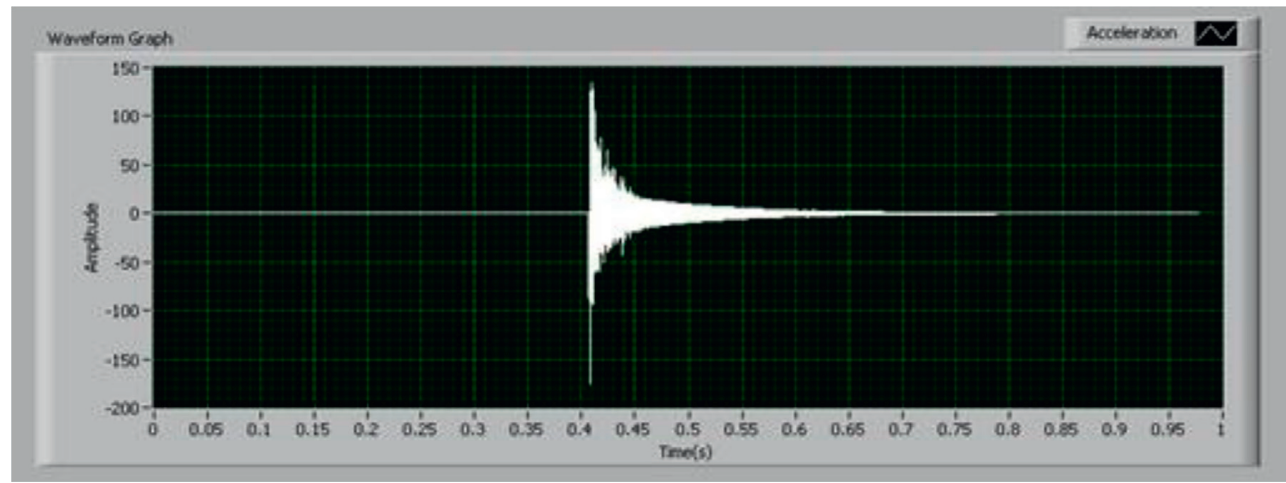

FIgURE 5: Time (sec) domain excitation response of Mg alloy under natural frequency.

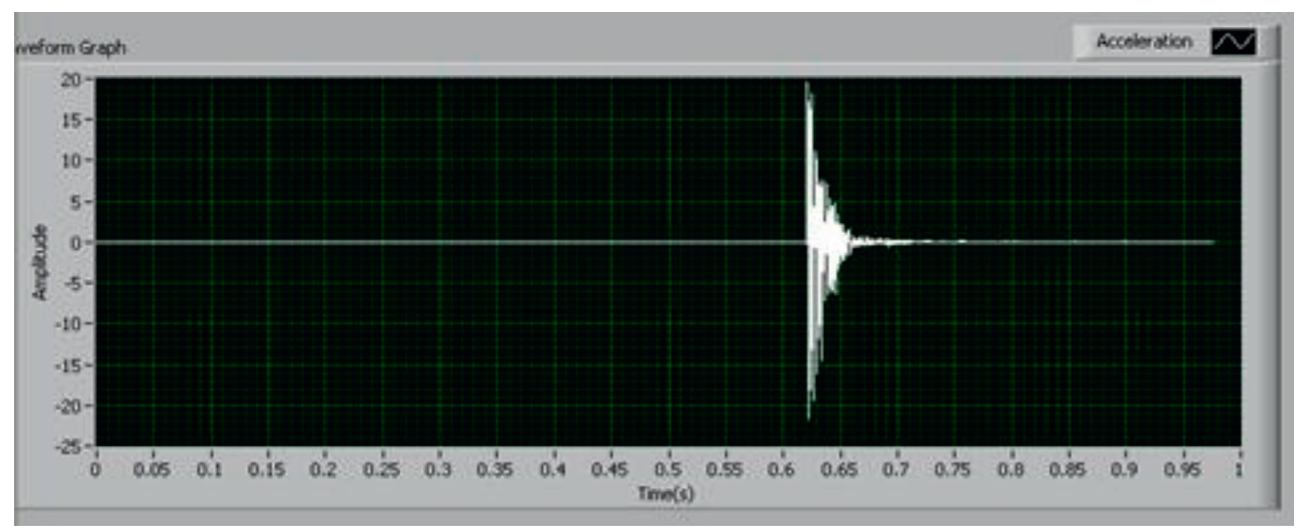

FIgURE 6: Time (sec) domain excitation response of A3 steel under loading condition (4 kg).

Figures 8 and 9 show the free frequency response of A3 steel and $\mathrm{Mg}$ alloy swivel plate obtained from the LABVIEW software. The values of the natural frequency of both materials of swivel plates are tabulated in Tables 5 and 6.

Figures 10 and 11 show the frequency response of A3 steel and $\mathrm{Mg}$ alloy swivel plate under loading condition $(4 \mathrm{~kg})$ obtained from the LABVIEW software. The values of frequency for both materials of swivel plates under different loading conditions with four location points were taken from the vibration setup and the values are tabulated in Tables 7 and 8 .

The natural frequency values for both materials of swivel plates were taken in the four location points and are tabulated in Tables 5 and 6 . From these numbers of location points readings were taken for obtaining the accurate value for natural frequency. Moreover, the four location points were the four corners of swivel plate. The four corners of swivel plate are shown in Figure 2.

The frequencies under different loading condition values for both materials of swivel plates were taken in the four location points and those are tabulated in Tables 7 and 8. These numbers of location points' readings were taken for obtaining the accurate value for frequency under different loading conditions, because the four corners are used to connect the car seat parts. Moreover, that area of the plate is only carrying the load when the weight was applied on the seat. 


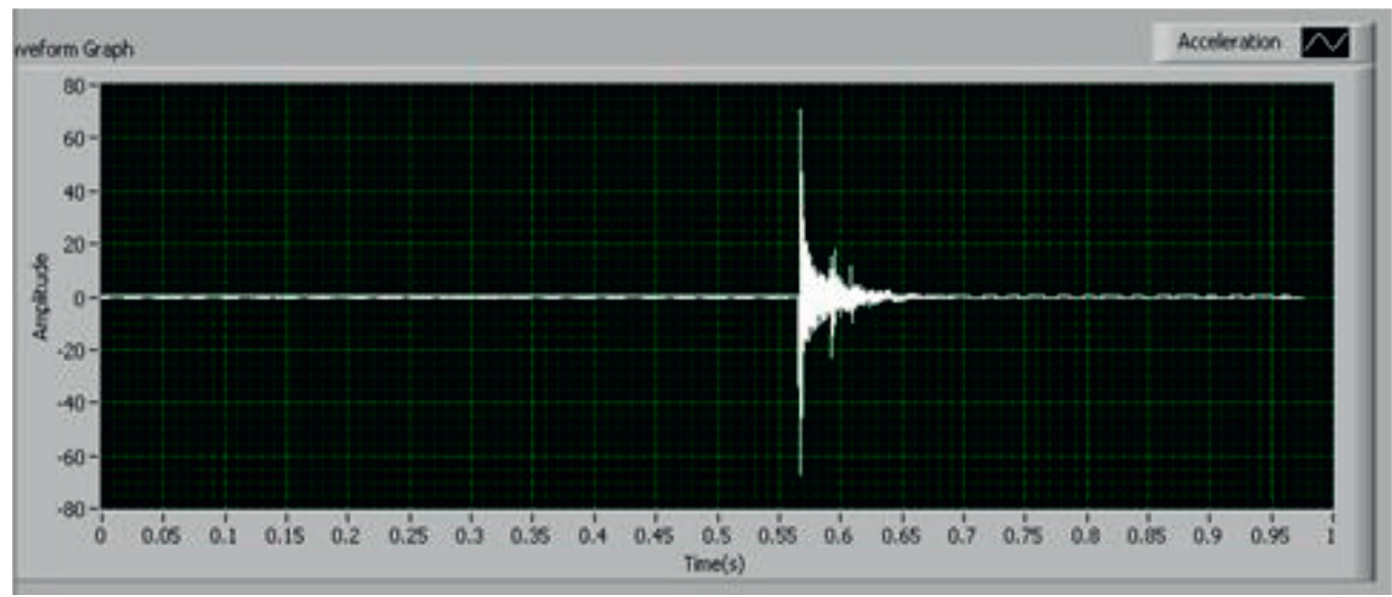

Figure 7: Time (sec) domain excitation response of $\mathrm{Mg}$ alloy under loading condition (4 kg).

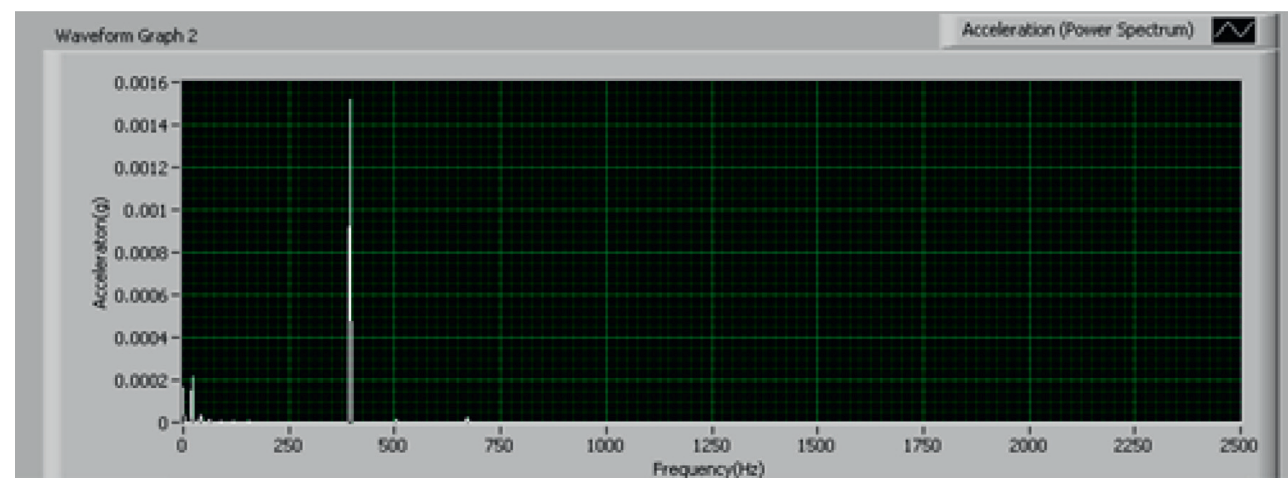

FIGURE 8: Frequency response of A3 steel swivel plate under no loading condition.

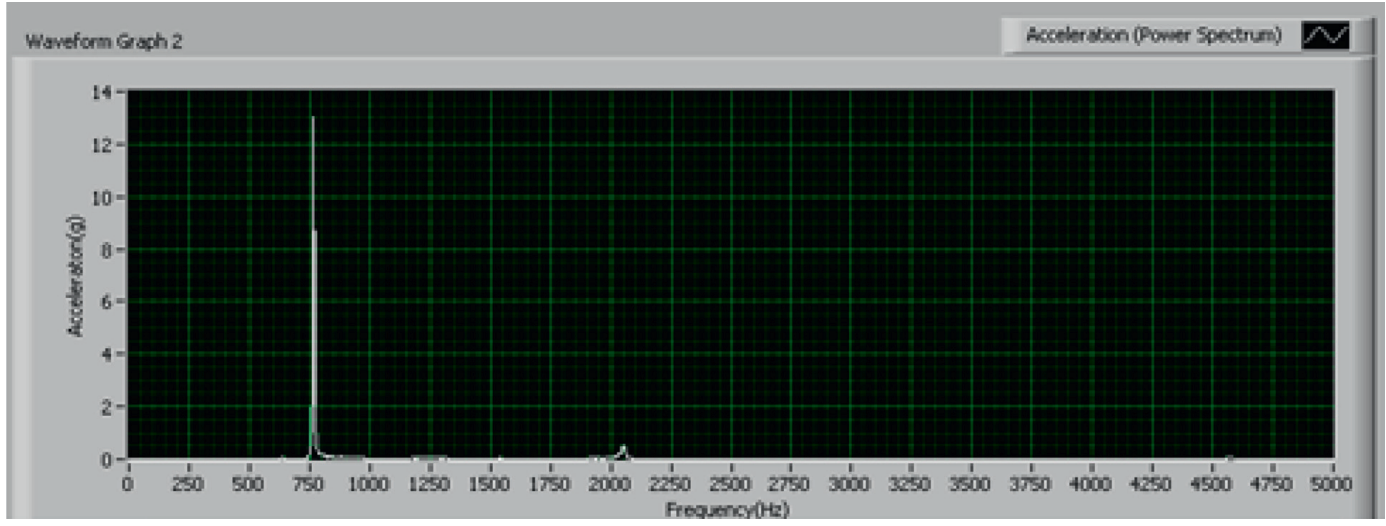

FIGURE 9: Frequency response of Mg alloy swivel plate under no loading condition.

TABLE 5: Natural frequency for A3 steel (with 4 location points).

\begin{tabular}{llc}
\hline S. no & Description & Natural frequency $(f)(\mathrm{Hz})$ \\
\hline 1 & Location 1 & 375 \\
2 & Location 2 & 380 \\
3 & Location 3 & 390 \\
4 & Location 4 & 390 \\
5 & Minimum value $(f)$ & 375 \\
\hline
\end{tabular}

TABLE 6: Natural frequency for Mg alloy (with 4 location points).

\begin{tabular}{llc}
\hline S. no & Description & Natural frequency $(f)(\mathrm{Hz})$ \\
\hline 1 & Location 1 & 765 \\
2 & Location 2 & 770 \\
3 & Location 3 & 760 \\
4 & Location 4 & 765 \\
5 & Minimum value $(f)$ & 765 \\
\hline
\end{tabular}




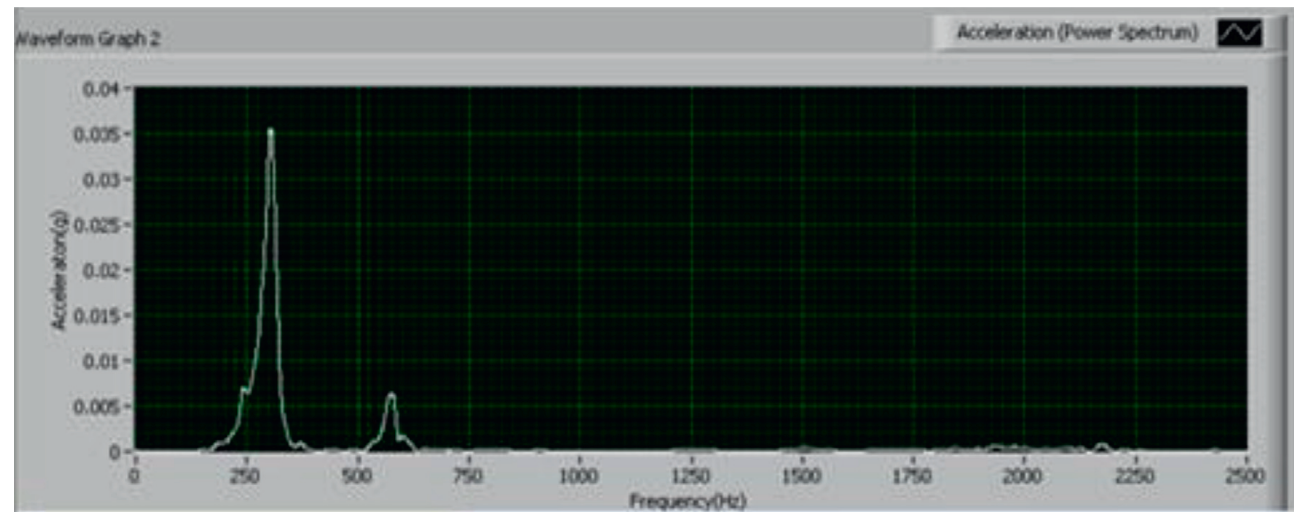

FIGURE 10: Frequency response of A3 steel swivel plate under loading condition $(4 \mathrm{~kg})$.

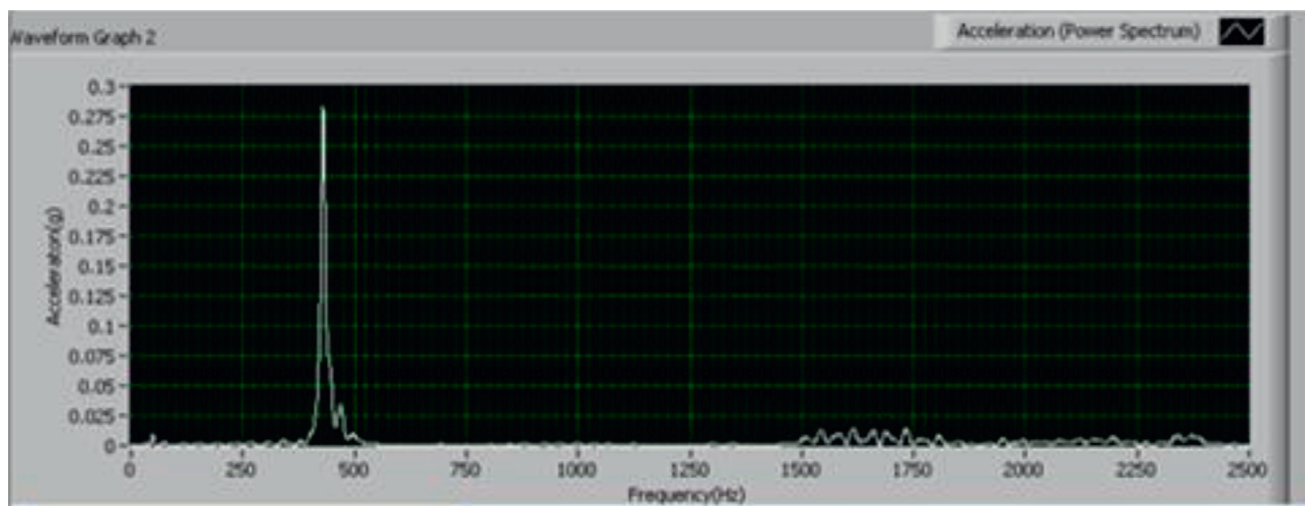

FIGURE 11: Frequency response of Mg alloy swivel plate under loading condition (4 kg).

TAвLE 7: Frequency under loading condition for A3 steel (with 4 location points).

\begin{tabular}{lcccccccc}
\hline $\begin{array}{l}\text { S. } \\
\text { no }\end{array}$ & Description & \multicolumn{6}{c}{ Frequency $(\mathrm{Hz})$} \\
\hline 1 & Location 1 & 325 & 300 & 280 & 245 & 210 & 180 & 145 \\
2 & Location 2 & 325 & 310 & 285 & 250 & 215 & 185 & 140 \\
3 & Location 3 & 335 & 300 & 285 & 250 & 210 & 185 & 140 \\
4 & Location 4 & 335 & 290 & 285 & 250 & 215 & 185 & 145 \\
& Maximum value & 335 & 310 & 285 & 250 & 215 & 185 & 145 \\
\hline
\end{tabular}

TABLE 8: Frequency under loading condition for Mg alloy (with 4 location points).

\begin{tabular}{lcccccccc}
\hline $\begin{array}{l}\text { S. } \\
\text { no }\end{array}$ & \multirow{2}{*}{ Description } & $2 \mathrm{~kg}$ & $4 \mathrm{~kg}$ & $6 \mathrm{~kg}$ & $8 \mathrm{~kg}$ & $10 \mathrm{~kg}$ & $20 \mathrm{~kg}$ & $30 \mathrm{~kg}$ \\
\hline 1 & Location 1 & 615 & 430 & 265 & 135 & 85 & 50 & 35 \\
2 & Location 2 & 620 & 435 & 270 & 135 & 80 & 55 & 35 \\
3 & Location 3 & 620 & 435 & 270 & 135 & 80 & 55 & 35 \\
4 & Location 4 & 615 & 425 & 260 & 130 & 80 & 50 & 35 \\
& Maximum value & 620 & 435 & 270 & 135 & 85 & 55 & 35 \\
\hline
\end{tabular}

\section{Sound Absorption Measurement Analysis}

The sound absorption analysis is a very important one because the material has the ability to absorb unwanted noise inside the car. Moreover, this analysis used to evaluate the noise effect for the magnesium alloys. The sound absorption coefficient was measured by using an impedance tube tester as per the ASTM E 1050. In order to find the sound absorption capacity of both materials, a circular disc specimen was prepared because the sound propagation cylinder is in cylindrical shape. The dimensions of the sound test specimen for both materials are presented in Table 9.

5.1. Experimental Method. The impedance tube testing method was carried out by the generation of plane wave in a cylindrical tube by a sound source. The sound pressures are measured in a microphone position in close proximity of the test sample [26].

An impedance tube tester was utilized to find out sound absorption coefficient $(\alpha)$ for both materials. The impedance tube has sound source (loud speaker) at one side end and test sample was mounted on another end. The dimensions of the test sample for both materials are presented in Table 10. The loudspeaker produces broadband random sound waves and the sound waves are propagating as plane waves in the tube; those plane waves hit the sample, get partially absorbed, and subsequently reflected. The sound absorption properties of both materials sample were tested in the frequency range of $100-2000 \mathrm{~Hz}$. This system tests a sound absorptive material, processes the results, and reports the results in a graph of the absorption coefficient in various frequencies. Thus, the 
TABle 9: Dimensions and Weight of Specimen for sound absorption analysis.

\begin{tabular}{lcccc}
\hline S. no & Material & Diameter of the plate $(\mathrm{mm})$ & Thickness $(\mathrm{mm})$ & Weight $($ grams $)$ \\
\hline 1 & A3 steel & 100 & 1.5 & 95 \\
2 & Mg alloy & 100 & 5 & 71 \\
\hline
\end{tabular}

TABLe 10: Natural frequency values of both materials.

\begin{tabular}{lccc}
\hline \multirow{2}{*}{ S. no } & \multirow{2}{*}{ Analysis $(\mathrm{Hz})$} & \multicolumn{2}{c}{ Experimental $(\mathrm{Hz})$} \\
& & Steel & Mg alloy \\
\hline 1 & Natural frequency $(f)$ & 375 & 765 \\
\hline
\end{tabular}

sound absorption coefficient of each material sample was obtained.

The ability of both materials to absorb unwanted noise is based on dissipation of the sound energy upon passing through the material and also on conversion of some of the energy into heat. The sound absorption coefficient $(\alpha)$ was calculated as the amount of original energy less than the remaining unabsorbed energy compared to the original energy leads to the measurement.

\section{Results and Discussion}

The behavior of AZ91D-Mg alloy and A3 steel swivel plate and specimen has been successfully studied and the following observations were made.

6.1. Flexural Strength Analysis. From the flexural test, the load vs. extension response of AZ91D and A3 steel specimen was studied. By using strength and modulus formulas, flexural strength and flexural modulus for both materials were calculated. The flexural load-extrusion response of A3 steel, load values increase linearly in the elastic region. Maximum stress occurs at the mid span in three-point bending configuration [27]. Above the maximum stress, the steel plate gets rapture and failure occurs. The average flexural strength and flexural modulus values of the A3 steel ware found to be 4.326 $\mathrm{Mpa} \pm 0.085 \mathrm{MPa}$ and $102.45 \mathrm{Mpa} \pm 15.05 \mathrm{Mpa}$, respectively. For the flexural load-extrusion response of AZ91D-Mg alloy, the average flexural strength and flexural modulus values were found to be $7.078 \pm 0.145 \mathrm{MPa}$ and $180.45 \pm 7.05 \mathrm{Mpa}$, respectively. The values are plotted in the bar chart as shown in Figures 12 and 13.

From Figure 12, it is observed that the flexural strength of AZ91D-Mg alloy exhibits better than that of A3 steel. It is also observed that the flexural modulus of $\mathrm{Mg}$ alloy is better than that of A3 steel from Figure 13. The bending test consists of tension, compression, and shear forces. Both materials were tested along the $y$-direction and they gradually experienced brittle failure in the tensile surface. Due to the bending moment, the middle section of the tensile surface of the rupture occurred. Until the specimen failure, large deflection was achieved. Moreover, during this analysis the $\mathrm{Mg}$ alloy exhibits better performance than that of A3 steel.

6.2. Stiffness Analysis. The load and deflection values were obtained from experiential method and plotted in curve as

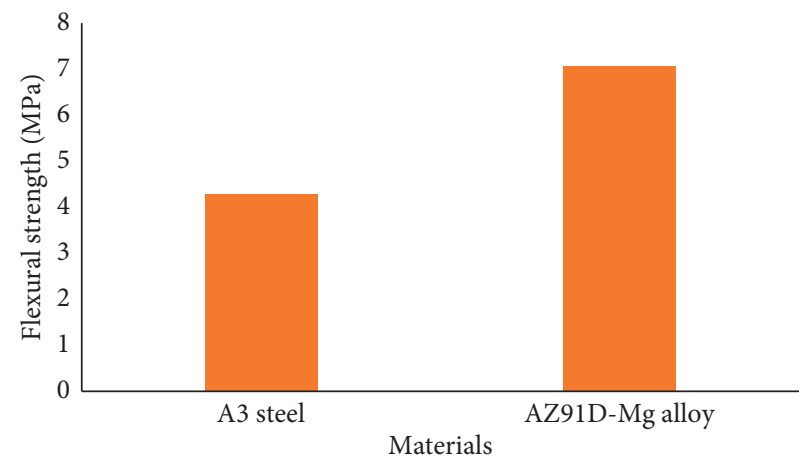

Figure 12: Flexural strength for both materials.

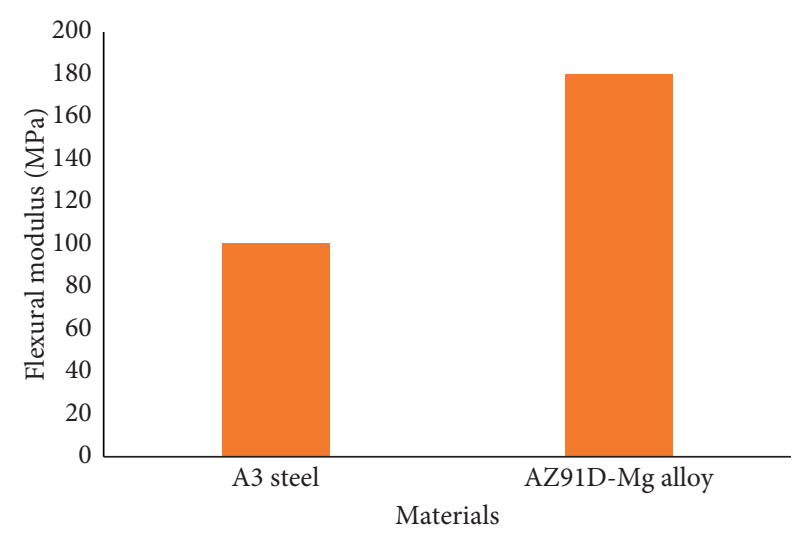

Figure 13: Flexural modulus for both materials.

shown in Figure 3. Moreover, the stiffness values were obtained by using the experimental values. It is revealed that the specific stiffness value of AZ91D swivel plate is significantly higher when compared to that of A3 steel plate [28]. This is due to its mechanical property of $\mathrm{Mg}$ alloy; it exhibits better stiffness when compared to steel under loading condition. However, the load carrying capacity of AZ91D swivel plate was significantly higher when compared to A3 steel plate with the current dimension condition.

It could be seen from Figure 3 that the deflection value of AZ91D swivel plate is significantly lower than that of A3 steel plate. This is because the thickness of Mg alloy plate is high and the steel exhibits poor performance when compared to $\mathrm{Mg}$ alloy when it is subjected to bending [29].

The simple numerical analysis for finding out the mechanical advantage of the swivel plate was presented here. Let us consider the mechanical advantage $(R)$ for both materials of swivel plate; also the upper plate of the swivel plate was chosen for this numerical analysis.

Now, let us assume that the applied loads are the same: 


$$
R=\frac{\sigma_{\text {Steel }}}{\sigma_{\mathrm{Mg} \text { alloy }}}=\frac{(M I / y)_{\text {steel }}}{(M I / y)_{\mathrm{Mg}}}=\frac{y_{\mathrm{Mg}} * M_{\text {streel }} * I_{\text {steel }}}{y_{\text {steel }} * M_{\mathrm{Mg}} * I_{\mathrm{Mg}}},
$$

where $M$ is the bending moment, $I$ is themoment of inertia, and $y$ is the distance between the uppermost fiber of the plate and the neutral axis are indicated. From this relation, let us assume that the moment is the same for both materials and the " $y$ " value for both material plates has very less amount. Moreover, the dimensions of both plates are equal, but the thickness of the $\mathrm{Mg}$ alloy plate is larger than that of the steel so that $I_{\mathrm{Mg}}>I_{\text {steel. }}$. If you consider the mechanical advantage relation, the numerator part has lesser value and the denominator part has the highest value. Finally, we get a better mechanical advantage for $\mathrm{Mg}$ alloy plate when compared to steel from this relation.

For a thicker, less density material can be determined by considering the ratio of the stress equation (3), also this method can be used to choose material with the best properties for particular mechanical component. From the mechanical advantage $(R)$, it could be seen that Mg alloy exhibits better geometric advantage over the A3 steel for the current dimension condition. Even, the mg alloy swivel plate has less weight cross section when compared to A3 steel for current analysis; it performs better. If it has equal weight cross section of steel, the performance of the $\mathrm{Mg}$ alloy material will be superior to that of steel when it is subjected to bending. Even if the yield strength of the steel is higher than the $\mathrm{Mg}$ alloys, the $\mathrm{Mg}$ alloy carries high amounts of load when it is subjected to bending because of better geometric and strength advantage when compared to steel. From that experimental and numerical analysis, the results revealed that the AZ91D-Mg alloy swivel plate performed better than that of steel in terms of load carrying capacity and behavior in bending. Also, the flexural rigidity $\left(E I_{\mathrm{mg}}\right)$ of $\mathrm{Mg}$ alloy plate showed higher flexural rigidity $\left(E I_{\text {st }}\right)$ than that of steel plate.

6.3. Vibration Analysis. From the vibration analysis in experimental method the following observations were made. Table 10 shows the natural frequency of both materials in experimental methods and Tables 11 and 12 show the frequency under different loading conditions of both materials in the experimental method. For the natural frequency in the experimental method, minimum values were taken, whereas for loading condition, maximum frequency value was taken because in the natural frequency the componant tends to oscilate without any damping force so that we choose lowest value, whereas under loading condition always choose maximum value.

(i) From Table 10, it can be seen that Mg alloy material exhibits higher than that of A3 steel under the same excitation pulse input, because the natural frequency of the structure is controlled by mass and stiffness. In this case, the mass of the AZ91D is lower than A3 steel (Table 3).

(ii) From Tables 11 and 12, it can be seen that the vibration absorption capacity of $\mathrm{Mg}$ alloy swivel plate exhibits better than that of A3 steel under loading
TABLE 11: Frequency under loading condition in experimental method for A3 steel.

\begin{tabular}{lccccccccc}
\hline & \multicolumn{8}{c}{ Frequency $(\mathrm{Hz})$} \\
S. no & Method & \multicolumn{8}{c}{ A3 steel } \\
& & $2 \mathrm{~kg}$ & $4 \mathrm{~kg}$ & $6 \mathrm{~kg}$ & $8 \mathrm{~kg}$ & $10 \mathrm{~kg}$ & $20 \mathrm{~kg}$ & $30 \mathrm{~kg}$ \\
\hline 1 & Experimental & 335 & 310 & 285 & 250 & 215 & 185 & 145 \\
\hline
\end{tabular}

TABLE 12: Frequency under loading condition in experimental method for $\mathrm{Mg}$ alloy.

\begin{tabular}{|c|c|c|c|c|c|c|c|c|}
\hline \multirow{3}{*}{ S. no } & \multirow{3}{*}{ Method } & \multicolumn{7}{|c|}{ Frequency $(\mathrm{Hz})$} \\
\hline & & \multicolumn{7}{|c|}{ AZ91D-Mg alloy } \\
\hline & & $2 \mathrm{~kg}$ & $4 \mathrm{~kg}$ & $6 \mathrm{~kg}$ & $8 \mathrm{~kg}$ & $10 \mathrm{~kg}$ & $20 \mathrm{~kg}$ & $30 \mathrm{~kg}$ \\
\hline 1 & Experimental & 620 & 435 & 270 & 135 & 85 & 55 & 35 \\
\hline
\end{tabular}

condition. It reflects that it has a high damping capacity than that of A3 steel material.

From Tables 11 and 12, the frequencies under different loading condition values for both materials were taken and plotted in a curve, given in Figure 14.

(i) From Figures 6 and 7, it is observed that under loading condition the $\mathrm{Mg}$ alloy exhibits better vibration amplitude attenuation response excitation than that of steel. So in order to increase the load for swivel plate the Mg alloy gave better time domain response when compared to A3 steel. It is revealed that $\mathrm{Mg}$ alloy material has better vibration absorbing capacity under loading condition when compared to A3 steel.

(ii) Figure 14 shows the relation between load and frequency under different loading conditions of both materials. It could be seen that the initial frequency of $\mathrm{Mg}$ alloy plate was maximum when compared to A3 steel plate. After that, while increasing the load, it comes below that of the A3 steel plate; it is observed that while increasing the load the vibration observing capacity of $\mathrm{Mg}$ alloy plate is significantly increased. The result illustrates that it has high damping observing capacity when it is subjected to loading condition [30,31].

(iii) It is also observed that, at the intersect point "Q", i.e., up to $5 \mathrm{~kg}$, and the corresponding frequency value of $300 \mathrm{~Hz}$, the $\mathrm{Mg}$ alloy swivel plate exhibits poor damping capacity and after that particular point " $Q$ ", the $\mathrm{Mg}$ alloy exhibits superior damping capacity to that of A3 steel. Moreover, critical load and two stages were observed from Figure 14; at load of $10 \mathrm{~kg}$ (critical load) stage 1 changes over into stage 2. At stage1, the frequency rate suddenly decreased with respect to load and at stage 2 it gradually decreased. It is revealed that the $\mathrm{Mg}$ alloy swivel plate enters into steady state stage at the load of $10 \mathrm{~kg}$ (critical load).

(iv) The result revealed that the weight of the car seat that is applied on the swivel plate should be more than $10 \mathrm{~kg}$. The Mg alloy swivel plate only exhibits 


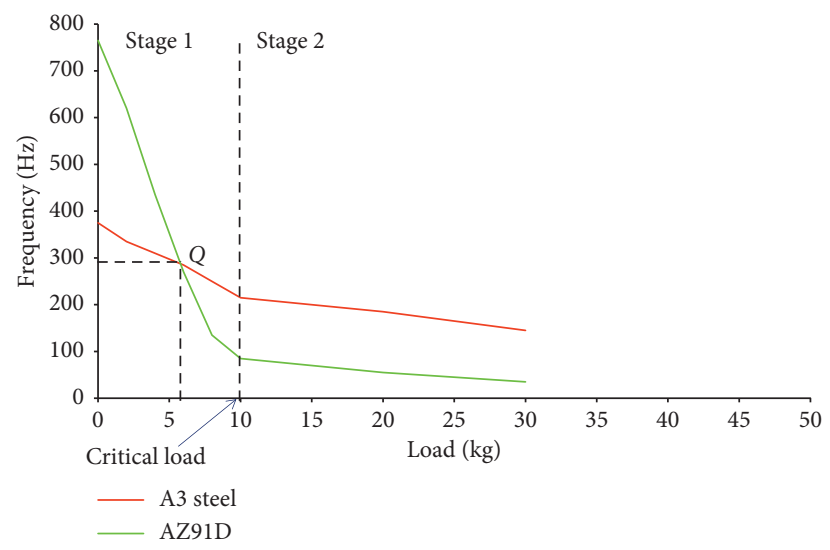

Figure 14: Frequency under different loading conditions for both materials swivel plate.

TABle 13: Sound absorption coefficient $(\alpha)$ for both materials.

\begin{tabular}{lcccc}
\hline S. no & Frequency & Steel & Mg alloy & Ratio \\
\hline 1. & Low level $(100 \mathrm{~Hz})$ & 0.04 & 0.05 & $25 \%$ increased \\
2 & High level $(2000 \mathrm{~Hz})$ & 0.17 & 0.19 & $11.76 \%$ increased \\
\hline
\end{tabular}

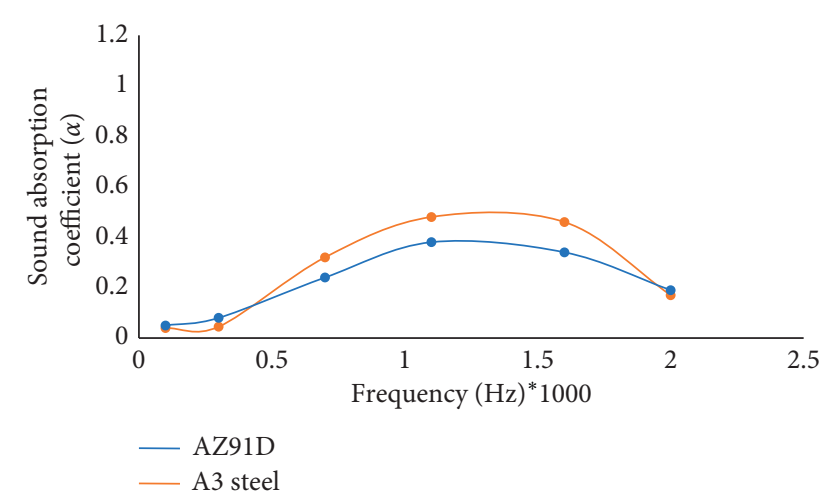

FIGURE 15: Sound absorption coefficient $(\alpha)$ vs. frequency $(\mathrm{Hz})$ for both materials.

better damping capacity. Moreover, the seat occupied by humans will provide better comfort while the vehicle is under dynamic condition.

(v) AZ91D-Mg alloy exhibits high damping capacity due to its material nature and alloying elements, given in Table 1. The addition of aluminum improves strength, hardness, and corrosion resistance. Addition of zinc is next to aluminum in effectiveness as an alloying ingredient to strengthen Magnesium. Also addition of small amount of $\mathrm{Mn}, \mathrm{Si}$, and $\mathrm{Cu}$ improves the strength and mechanical properties of AZ91D alloy.

(vi) Chen et al. [17] had investigated the effect of mechanical vibration on microstructure and properties of AZ91D; they concluded that with the increase of mechanical amplitude the tensile and yield strength increased gradually. Because of that, AZ91D alloy showed better performance when subjected to vibration. (vii) For the swivel plate of the same structure of these two materials, the time domain response and exciting point are mainly controlled by the elastic modulus of the material. The AZ91D elastic modulus is significantly less and the stiffness is higher than that of A3 steel. Because of high stiffness, the AZ91D exhibits lower response amplitude for external excitation. Because of that, $\mathrm{Mg}$ alloy exhibits high damping capacity in structural application.

6.4. Sound Absorption Measurement Analysis. In this section, the sound insulation capacity of both materials was analyzed. According to the experimental results the sound absorption coefficient $(\alpha)$ was obtained in all frequency levels. The lower level frequency $(100 \mathrm{~Hz})$ and higher level frequency $(2000 \mathrm{~Hz})$ values are presented in Table 13.

To analyze the sound absorption capacity of $\mathrm{Mg}$ alloy and A3 steel with the same sound waves input, the comparison test of sound absorption coefficient $(\alpha)$ was performed using the specimens made of AZ91D and A3 steel. The relationship between sound absorption coefficients $(\alpha)$ and frequency $(\mathrm{Hz})$ was plotted in the curve as shown in Figure 15.

From Figure 15, it is revealed that the AZ91D showed poor performance at middle and high frequency levels than A3 steel. According to acoustic theories, sound absorbing performance of the material at middle and high frequency levels depends on mass. In addition the damping capacity and stiffness of the material are important factors for controlling the structural NVH effect. The mass of Mg alloy specimen is significantly low when compared to A3 steel specimen (Table 9). Finally, with this result, we observed that the sound absorption capacity of AZ91D is lower than that of A3 steel. However, at low frequency level and at the end of 
TABLE 14: Weight for both the materials.

\begin{tabular}{lcccc}
\hline S. no & Analysis (grams) & Steel & Mg alloy & of reduced \\
\hline 1 & Weight & 632 & 464 & 26.58 \\
\hline
\end{tabular}

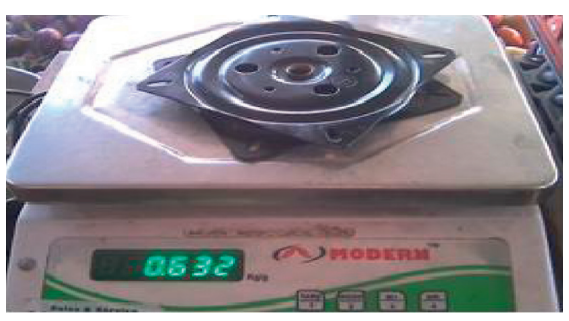

(a)

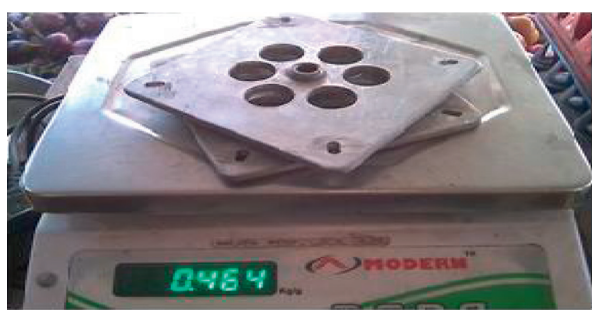

(b)

Figure 16: Weight difference between Mg alloy and A3 steel swivel plate. (a) Weight of A3 steel swivel plate. (b) Weight of Mg alloy swivel plate.

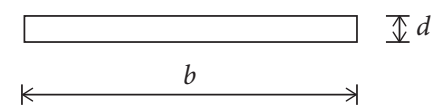

FIgURe 17: Cross section dimension of plate.

high frequency level the AZ91D exhibits better sound absorption performance. The reason is that $\mathrm{Mg}$ alloy has high stiffness (Figure 3) and better damping capacity (Figure 14) than A3 steel. The AZ91D-Mg alloy swivel plate will have a better sound insulation performance and better restraint for the low frequency booming noise of the car [18]. Moreover, the overall sound absorption performance of AZ91D-Mg alloy swivel plate has also reached the requirement of automotive industry based on the sound insulation application. By analyzing the influence of sound on the AZ91D-Mg alloy swivel plate, it can be found that it is suitable for car seat application.

\section{Conclusions}

(i) The AZ91D-Mg alloy swivel plate has a distinct mechanical advantage over A3 steel in terms of strength, stiffness, and load carrying capacity with greater flexural rigidity in current dimension conditions.

(ii) The flexural strength measurement test for the specimen is made of the AZ91D-Mg alloy and A3 steel, and the results showed that AZ91D exhibits better specific flexural strength and specific flexural modulus.

(iii) The AZ91D-Mg alloy swivel plate was performed very well in the time domain excitation response observation under different loading conditions; it is revealed that it exhibits better vibration observing capacity than A3 steel swivel plate while increasing load.

(iv) From Figure 14, load $10 \mathrm{~kg}$ was observed as a critical load. In order to increase seating comfort, the load applied on the swivel plate should be more than $10 \mathrm{~kg}$, because from the above observation the swivel plate exhibits good damping performance at higher values than the critical load value.

(v) In order to compare the sound absorption capacity for AZ91D and A3 steel the specimens were prepared and experiment was conducted using impedance tube tester. The results showed that the sound absorption coefficient $(\alpha)$ of AZ91D-Mg alloy material is $11.76 \%$ higher than that of A3 steel at higher frequency level $(2000 \mathrm{~Hz})$ and $25 \%$ higher at lower frequency level $(100 \mathrm{~Hz})$.

(vi) These results suggest that the AZ91D-Mg alloy material could be a viable candidate for better strength, sound, and vibration absorption application in automotive industry.

(vii) The weight of the swivel plate can be decreased by 26.58\% while AZ91D-Mg using alloy, when compared to A3 steel material (Table 14).

(viii) It is concluded that when using AZ91D-Mg alloy to replace A3 steel swivel plate, it is expedient to increase the mechanical advantage of the swivel plate and also stiffness, flexural strength, damping capacity, good acoustic behavior, and weight reduction.

\section{Appendix}

\section{A. Weight Ratio between Mg Alloy and A3 Steel}

Figure 16 shows the weight difference between A3 steel and $\mathrm{Mg}$ alloy swivel plate.

\section{B. Numerical Analysis of Bending for A3 Steel and AZ91D-Mg Alloy Plate}

For the numerical analysis the top part of the swivel plate was taken into consideration. Let us take those dimensions of the plates from Table 3 . 
Now consider the plate cross section dimension from Figure 17, where $b$ is the breadth and $d$ is the thickness of the plate. Moreover, " $y$ " value is very minimum, so that it is taken the same as both materials.

$$
\begin{aligned}
& I_{\text {steel }}=b d^{3} / 12=140 * 1.5^{3} / 12=29.25 \mathrm{~mm}^{4} . \\
& \text { Also, } I_{\mathrm{Mg}}=b d^{3} / 12=140 * 5^{3} / 12=1083.3 \mathrm{~mm}^{4} . \\
& \text { Mechanical Advantage } R=1083.3 / 29.25=37 \\
& \text { Flexural rigidity of } \mathrm{Mg} \text { plate } E I=45000 * 1083 \\
& \text { Flexural rigidity of steel plate } E I=205000 * 29.25 \\
& \text { Ratio of } E I \text { between } \mathrm{Mg} \text { alloy plate and steel } \\
& \text { plate }=45000 * 1083 / 295000 * 29.25=8
\end{aligned}
$$

From that, it could be seen that $\mathrm{Mg}$ alloy swivel plate has nearly 37 times better mechanical advantage and 8 times better flexural rigidity when compared to A3 steel in the current dimension conditions.

\section{Numerical Analysis of Vibration Absorption for A3 Steel and AZ91D-Mg Alloy Plate}

The relationship of the specific strain energy for the material as

$$
U=\frac{\sigma^{2}}{\rho E},
$$

where $\sigma$ is the strength, $\rho$ is thedensity, and $E$ is Young's modulus. From that relation, it could be clearly observed that the material having less density and modulus will have greater specific strain energy capacity. Form Table 2, it could be seen that the density and modulus values of $\mathrm{Mg}$ alloy were significantly lower than those of steel. Hence, the $\mathrm{Mg}$ alloy materials are such strong materials for such applications like vibration energy absorbing applications.

\section{Data Availability}

The data used to support the findings of this study are included within the article. Any additional data related to the paper may be requested from the corresponding author.

\section{Conflicts of Interest}

The authors declare that they have no conflicts of interest.

\section{Acknowledgments}

This work was carried out under the FIST Program 2015 Research Grant, No. SR/FST/College-279/2015, sponsored by the Department of Science and Technology (DST), Ministry of Science and Technology, India.

\section{References}

[1] G. S. Padden and M. F. Graffin, "Evaluation of whole-body vibration in vehicle," Journal of Sound and Vibration, vol. 253, no. 1, p. 195, 2002.
[2] S. V. Lamaka, M. F. Montemor, A. F. Galio et al., "Novel hybrid sol-gel coatings for corrosion protection of AZ31B magnesium alloy," Electrochimica Acta, vol. 53, no. 14, pp. $4773-4783,2008$.

[3] A. Saravanan and P. Suresh, "Finite element analysis of bending and dynamic response of a power transmission spur gear; advances in manufacturing technology (ICAMT2018)," in Advances in Manufacturing Technology, pp. 511-525, Springer, Berlin, Germany, Lecture Notes in Mechanical Engineering, 2019.

[4] S. Prabhakaran, V. Krishnaraj, M. S. kumar, and R. Zitoune, "Sound and vibration damping properties of flax fiber reinforced composites," Procedia Engineering, vol. 97, pp. 573581, 2014.

[5] M. Y. Zheng, K. Wu, M. Liang, S. Kamado, and Y. Kojima, "The effect of thermal exposure on the interface and mechanical properties of $\mathrm{Al}_{18} \mathrm{~B}_{4} \mathrm{O}_{33} \mathrm{w} / \mathrm{AZ}$ magnesium matrix composite," Materials Science and Engineering: A, vol. 372, no. 1-2, pp. 66-74, 2004.

[6] G. L. Song and A. Atrens, "Understanding magnesium corrosion-a frame work for improved alloy performance," Advanced Engineering Materials, vol. 5, no. 12, pp. 837-858, 2003.

[7] A. Pardo, M. C. Merino, A. E. Coy, F. Viejo, R. Arrabal, and E. Matykina, "Effect of Mo and Mn additions on the corrosion behaviour of AISI 304 and 316 stainless steels in $\mathrm{H}_{2} \mathrm{SO}_{4}$," Corrosion Science, vol. 50, no. 3, pp. 780-794, 2008.

[8] G. Pettersen, H. Westengen, R. Høier, and O. Lohne, "Microstructure of pressure die cast magnesium -4 wt.\% aluminum alloy modifies with rare earth additions," Materials Science and Engineering: A, vol. 207, no. 1, pp. 115-120, 1996.

[9] Z. Zhang, R. Tremblay, and D. Dube, "Microstructure and mechanical properties of ZA104 (0.3-0.6 Ca) die-casting magnesium alloys," Materials Science and Engineering A, vol. 385, no. 1-2, pp. 286-291, 2004.

[10] L. Shepeleva and M. Bamberger, "Microstructure of high pressure die cast AZ91D modified with Ca and Ce," Materials Science and Engineering: A, vol. 425, no. 1-2, pp. 312-317, 2006.

[11] M. E. Alam, A. M. S. Hamouda, Q. B. Nguyen, and M. Gupta, "Improving microstructural and mechanical response of new AZ41 and AZ51 magnesium alloys through simultaneous addition of nano-sized $\mathrm{Al}_{2} \mathrm{O}_{3}$ particulates and Ca," Journal of Alloys and Compounds, vol. 574, pp. 565-572, 2013.

[12] K. Suresh, K. P. Rao, Y. V. R. K. Prasad, N. Hort, and K. U. Kainer, "Microstructure and mechanical properties of as-cast Mg-Sn-Ca alloys and effect of alloying elements," Transactions of Nonferrous Metals Society of China, vol. 23, no. 12, pp. 3604-3610, 2013.

[13] D. Wan, J. Wang, and G. Yang, "A study of the effect of Y on the mechanical properties, damping properties of high damping Mg-0.6\% Zr based alloys," Materials Science and Engineering: A, vol. 517, no. 1-2, pp. 114-117, 2009.

[14] J. Wang, W. Wei, X. Huang, L. Li, and F. Pan, "Preparation and properties of $\mathrm{Mg}-\mathrm{Cu}-\mathrm{Mn}-\mathrm{Zn}-\mathrm{Y}$ damping magnesium alloy," Materials Science and Engineering: A, vol. 528, no. 21, pp. 6484-6488, 2011.

[15] G. Y. Yuan, Y. S. Sun, and W. J. Ding, "Effects of bismuth and antimony addition on the microstructure and mechanical properties of AZ91 magnesium alloy," Materials Science and Engineering: A, vol. 308, no. 1-2, pp. 38-44, 2001.

[16] G. Wu, Y. Fan, H. Gao, C. Zhai, and Y. P. Zhu, "The effect of $\mathrm{Ca}$ and rare earth elements on the microstructure, mechanical properties and corrosion behavior of AZ91D," Materials 
Science and Engineering: A, vol. 408, no. 1-2, pp. 255-263, 2005.

[17] J. Chen, X. Chen, and Z. Luo, "Effect of mechanical vibration on microstructure and properties of cast AZ91D alloy," Results in Physics, vol. 11, pp. 1022-1027, 2018.

[18] D. Wan, J. Wang, L. Lin, Z. Feng, and G. Yang, "Damping properties of Mg-Ca binary alloys," Physica B: Condensed Matter, vol. 403, no. 13-16, pp. 2438-2442, 2008.

[19] T. Han, G. Huang, Y. Wang, G. Wang, Y. Zhao, and F. Pan, "Enhanced mechanical properties of AZ31 magnesium alloy sheets by continuous bending process after V-bending," Progress in Natural Science: Materials International, vol. 26, no. 1, pp. 97-102, 2016.

[20] M. Habibnejad-Korayerm, M. K. Jain, and R. K. Mishra, "Microstructure modification and bendability improvement of AZ31 magnesium sheet by bending unbending and annealing process," Materials Science and Engineering: A, vol. 648, pp. 371-384, 2015.

[21] S. G. Pantelakis, N. D. Alexopoulos, and A. N. Chamos, "Mechanical performance evaluation of cast magnesium alloys for automotive and aeronautical applications," Journal of Engineering Materials and Technology, vol. 129, no. 3, pp. 422-430, 2007.

[22] L. Zhang, H. C. Shang, Z. Q. Zhao, and D. F. Zhang, "Evaluation of the dynamic characteristics of AZ91D crankcase covers and boxes," Strength of Materials, vol. 47, no. 1, pp. 128-135, 2015.

[23] B. H. Weijiu Huan, Y. Pang, and Z. Zhou, "Fretting wear behavior of AZ91D and AM60B magnesium alloys," Wear, vol. 260, no. 11-12, pp. 1173-1178, 2006.

[24] S. Schumann, "The paths and strategies for increased magnesium applications in vehicles," Materials Science Forum, vol. 488-489, pp. 1-8, 2005.

[25] K. Murali Mohan Rao, K. Mohana Rao, and A. V. Ratna Prasad, "Fabrication and testing of natural fibre composites: vakka, sisal, bamboo and banana," Materials and Design, vol. 31, no. 1, pp. 508-513, 2010.

[26] Z. Hong, L. Bo, H. Guangsu, and H. Jia, "A novel composite sound absorber with recycled rubber particles," Journal of Sound and Vibration, vol. 304, no. 1-2, pp. 400-406, 2007.

[27] Z. Ma, H. Zhao, M. Zhou et al., "Elasti-plastic bending properties of AZ31B magnesium alloy based on persistent tensile pre loads," Journal of Alloys and Compounds, vol. 708, p. 506, 2017.

[28] J. C. Benedyk, "Magnesium advances in automotive applications," Light Metal Age, vol. 63, p. 36, 2005.

[29] M. Easton, W. Qian Song, and T. Abbott, "A comparison of the deformation of magnesium alloys with aluminium and steel in tension, bending and buckling," Materials \& Design, vol. 27, no. 10, pp. 935-946, 2006.

[30] J. Zhang, Y. L. Tao, and Z. F. Sun, "Vibration damping capacity of AZ91D magnesium alloys," Chinese Journal of Mechanical Engineering, vol. 42, no. 10, p. 186, 2006.

[31] X. N. Zang, "Effect of reinforcements on damping capacity of pure magnesium," Journal of Materials Science Letters, vol. 22, p. 503, 2003. 